\title{
A Case of Geroderma Osteodysplasticum Syndrome: Unique Clinical Findings
}

\author{
${\text { Maha Alotaibi }{ }^{1 *} \text {, Deema Aldhubaiban }}^{2}$, Ahmed Alasmari $^{3}$, Leena Alotaibi ${ }^{4}$ \\ ${ }^{1}$ Department of Genetics, Children's Hospital, King Saud Medical City, Riyadh, Saudi Arabia \\ ${ }^{2}$ Resident - department of periodontology .King Saud Medical City, Riyadh, Saudi Arabia \\ ${ }^{3}$ Senior Orthodontic Resident, King Saud Medical City, Riyadh, Saudi Arabia \\ ${ }^{4}$ Medical Student, king Saud bin Abdul-Aziz University for health sciences
}

*Corresponding Author: Maha Alotaibi, Department of Genetics, Children's Hospital, King Saud Medical City, Riyadh, Saudi Arabia,

Received date: October 05, 2021; Accepted date: October 13, 2021; Published date: October 20, 2021

Citation: Maha Alotaibi, Deema Aldhubaiban, Ahmed Alasmari, Leena Alotaibi. (2021) A Case of Geroderma Osteodysplasticum Syndrome: Unique Clinical Findings. J Clinical Research and Reports, 9(2); DOI:10.31579/2690-1919/207

Copyright: (C) 2021 Maha Alotaibi. This is an open access article distributed under the Creative Commons Attribution License, which permits unrestricted use, distribution, and reproduction in any medium, provided the original work is properly cited.

\begin{abstract}
Geroderma osteodysplasticum (GO; MIM 231070) is characterized by a typical progeroid facial appearance, wrinkled, lax skin, joint laxity, skeletal abnormalities with variable degree of osteopenia, frequent fractures, scoliosis, bowed long bones, vertebral collapse, and hyperextensible fingers. The disorder results from mutations in the GORAB - golgin, RAB6 interacting. This gene encodes a member of the golgin family, a group of coiled-coil proteins on golgin. That maps to chromosome 1q24. The encoded protein has a function in the secretory pathway. Was identified by-teIrminal kinase-like protein, and thus it may function in mitosis? [13] Mutations in this gene have been associated with geroderma osteodysplastica. Herein, we describe the clinical presentation of one young male patient from related Saudi parents. mutations, a homozygous Frameshift mutation (c.306dup p.(pro 103 Thrfs*20) Interestingly, phenotypic variability was observed in this patient with GO features that were atypical than the cases reported in the literature [9] as he looks tall stature where the most of cases reported were short and arachnodactyly of fingers which mimic and other syndromes
\end{abstract}

Keywords: geroderma osteodysplasticum syndrome; lax skin; hyperextensible fingers; progeria; scoliosis; loose joints; abnormal hair

\section{Introduction}

Geroderma osteodysplastica (GO; OMIM 231070) is a rare autosomal recessive disorder of the connective tissue. Was delineated by Bamatter et al. [2] in five members of a Swiss family. That family has been reviewed for over 20 years $[3,4]$ Those patients had facial dysmorphism, hyperlaxity of skin facies looks a droopy, prematurely aged appearance, The eyelids and cheeks droop. the forehead is prominent, the nose is often prominent and fleshy, maxillary hypoplasia osseous changes, variable severity of osteoporosis, hyperextensible joints, kyphoscoliosis, bone fractures and vertebral collapse, dental, CONGENITAL HIP dislocation. The disorder frequents in the Middle East and mainly in Oman. About 60 cases have been published to date [11]

The clinical phenotype of GO overlaps a heterogeneous group of disorders of the skin [5] including Cutis laxa syndromes, autosomal dominant cutis laxa (ADCL; MIM \#123700), autosomal recessive cutis laxa (ARCLI; MIM \#219100, ARCLII; MIM \#219200, ARCLIII; MIM \#219150), and wrinkly skin syndrome (WSS; MIM \#278250) [6]
The GO disorder is due to the mutation of a gene that encodes for a Golgi apparatus protein called GORAB. The physiological function of GORAB is poorly defined. The golgin, RAB6-interacting (GORAB) protein localizes to the Golgi apparatus and interacts with the small GTPase RAB6 [7].GORAB is important for vesicle transport at the Golgi complex and the correct processing of sugar chains on cargo proteins transiting through this compartment. Underlying defect of the skin and bone defects in GO patients is due to impaired COPI (coat protein complex I) trafficking at the Golgi apparatus resulting in abnormal glycosylation of extracellular matrix composition.

\section{Clinical report}

This 'A 24 year' Saudi male (Fig. 1) was born at term via breech vaginal delivery after limited antenatal care to a primigravida mother. He is a product of consanguineous healthy parents and the family history was negative for congenital malformations or deaths. He was seen initially in the dental clinic with generalized gingivitis gingival recession and severe crowding. Fig. 1. with dysmorphic facial features The facial features 
consisted of progeroid appearance, long triangular face deep-set eyes, droopy cheek, mid-face hypoplasia, mandibular prognathism, large prominent, a fleshy tip of the nose and prominent ears, hyperextensible fingers, arachnodactyly fingers and toes with the appearance of wrinkly skin, prominent veins in the dorsum of the hands., abdomen and joint laxity, His height was $187.6 \mathrm{~cm}$ and weight was $73.4 \mathrm{~kg}$. Her upper: lower segment ratio was 0.81 . Region. In addition, she had scoliosis with marked joint laxity. Radiological and skeletal findings support the diagnosis of GO Radiographs Figure. 2. DEXA scan showed a decrease in bone density (total lumbar spine (L1-L4) Z score -3.1; total right femur, $\mathrm{Z}$ score -2.5). No history of fracture and no recent hospitalization $\mathrm{He}$ is a college student with good performance, normal intelligence

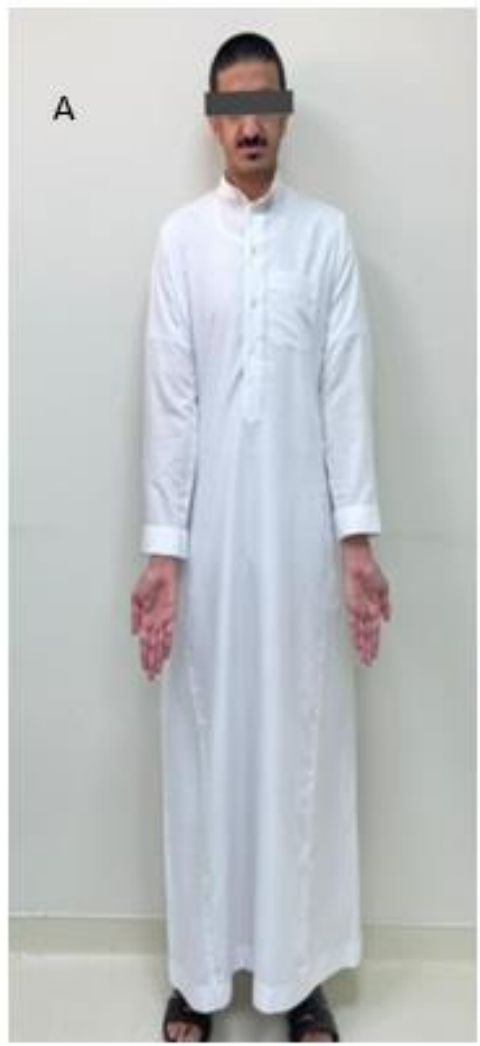

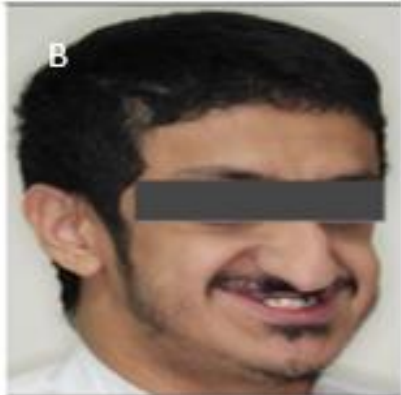
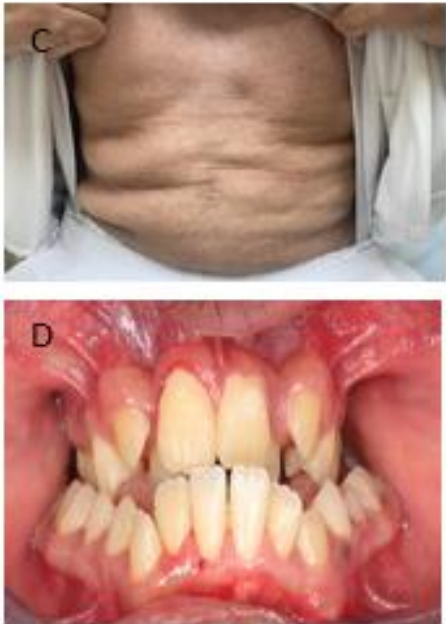
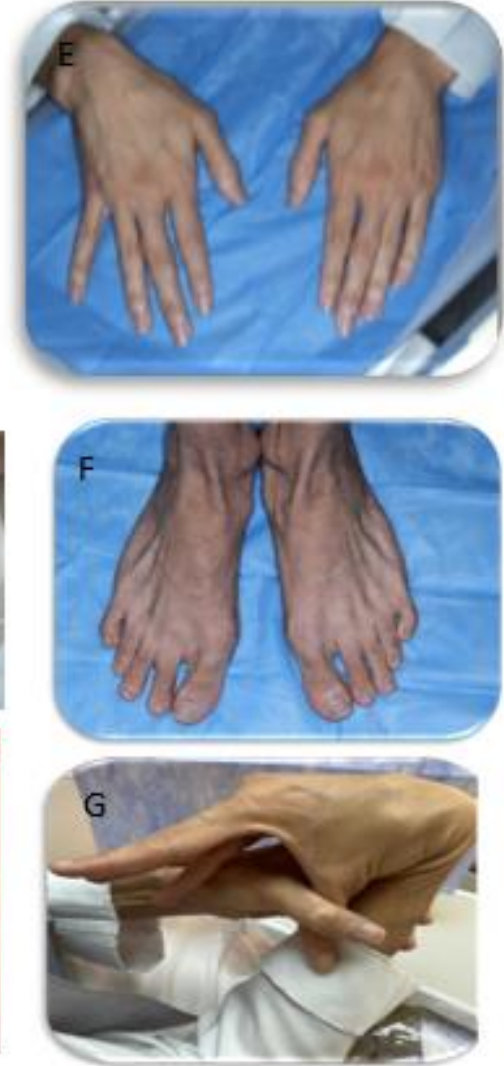

Figure 1 A: Photograph of the patient showing tall stature, long face, arm span greater than height $\mathbf{B}:$ Typical facial features of Patient include senile appearance, long and droopy' face, mid-face hypoplasia, mandibular prognathism, large prominent, a fleshy tip of the nose and prominent ears. , C wrinkly skin on the abdomen D showing generalized gingivitis and Severe crowding. E, F, G Showing Hyperextensible fingers, arachnodactyly and wrinkly skin, prominent veins on the dorsum of the hands and the foot
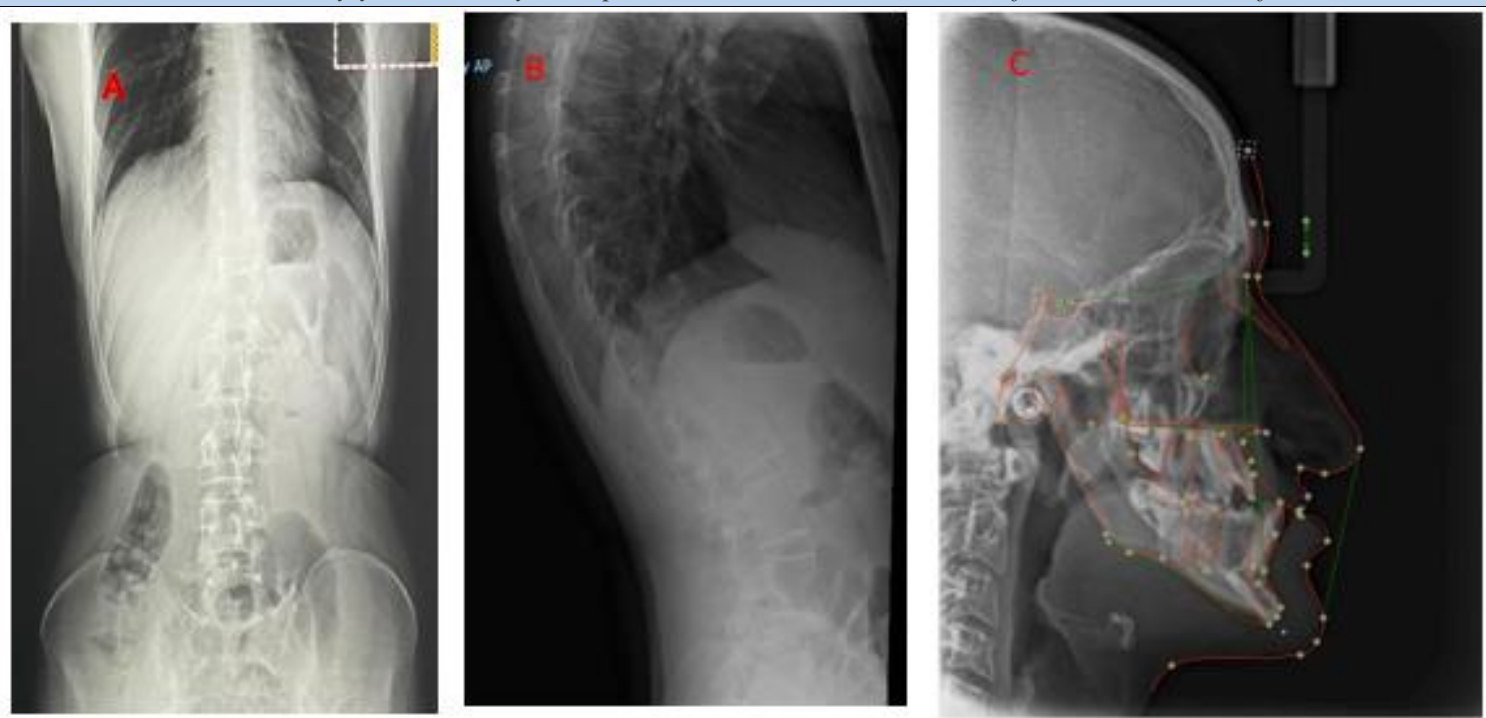

Figure 2: Radiological characteristics A, B, C radiographs of patient Maintained thoracic kyphosis \& lumbar lordosis. Diffuse decreased bone density; osteoporosis. Decreased height of T-7, 8, 9 \& T-12 vertebral bodies. Normal height \& alignment of the other vertebral bodies. C Lateral cephalometric showed severe Cl lll malocclusion due to combination between retrognathic maxilla and prognathic mandible 


\begin{tabular}{|lllc|}
\hline Mutation & Ethnicity & Nucleotide change & Reference \\
\hline Missense & Saudi & $658 \mathrm{G}>\mathrm{C}, \mathrm{p} . \mathrm{A} 220 \mathrm{P})$ & 10 \\
Nonsense & Germany & $136 \mathrm{G}>\mathrm{T}$ p Glu46X) & 13 \\
Nonsense & Libya & $190 \mathrm{C} 4 \mathrm{~T}$ & 13 \\
Nonsense & Canada & $367 \mathrm{G} 4 \mathrm{~T}$ & 13 \\
Nonsense & Mexico & $367 \mathrm{G} 4 \mathrm{~T}$ & 13 \\
Nonsense & Italy & $739 \mathrm{C} 4 \mathrm{~T}$ & 13 \\
Nonsense & United State & $784 \mathrm{C} 4 \mathrm{~T}$ & 13 \\
Splicing & United State & $662+5 \mathrm{G} 4 \mathrm{C}$ & 13 \\
Small deletion & Germany & $1050 \_1053$ delTCTT & 13 \\
Small insertion & Saudi & 226227 insA & 13 \\
Small indls & Pakistan & -1 1GA4CT & 14 \\
Gross deletion & Azerbaijan & (breakpoint between chr1 & \\
& & $: 164037509-170654598$ bp & \\
& & on chr 1q23.2-q24.2) & \\
\hline
\end{tabular}

Table 1: GORAB mutations in different ethnic groups causing GO syndrome

\section{Discussion}

- Gerodermia osteodysplastica was first described by Bamatter et al [2] in five members of a Swiss family and he referred to them as Walt Disney dwarfs. It is inherited as an autosomal recessive disorder caused by mutations in the Golgin, RAB6-interacting (GORAB) gene on chromosome 1q24, which encodes a protein important for Golgi-related transport[12]

- The characteristics features of GO include the skin changes suggestive of premature aging, and various skeletal changes including osteoporosis, vertebral deformity, and fractures. The patient described here has old age facial appearance tall stature, all of the cases have been reported ware normal or short stature $[3,7,10]$ wrinkled skin, mainly over the dorsum of the hand, laxity joint and he had osteoporosis, kyphoscoliosis, a reduced upper/lower segment ratio, no history of fractures, and severe periodontal disease including Generalized gingivitis, Gingival recession, and severe crowding. With normal intelligence even there were patients reported with GO to be mental retarded [10] Indeed, whole-exome sequencing was done for the patient and written consent was obtained from the patient for the analysis. Sample collection and DNA extraction Whole blood samples $(5 \mathrm{e} 10 \mathrm{ml})$ from the affected patient.

- Genomic DNA is enzymatically fragmented, and target regions are enriched using DNA capture probes. These regions include approximately $41 \mathrm{Mb}$ of the human coding exome (targeting > $98 \%$ of the coding RefSeq from the human genome build GRCh37/hg19), as well as the mitochondrial genome. The generated library is sequenced on an Illumina platform to obtain at least 20x coverage depth for $>98 \%$ of the targeted bases. An in-house bioinformatics pipeline, including reading alignment to GRCh37/hg19 genome assembly and revised Cambridge Reference Sequence (rCRS) of the Human Mitochondrial DNA (NC_012920), variant calling, annotation, and comprehensive variant filtering is applied. All variants with minor allele frequency (MAF) of less than 1\% in gnomAD database and disease-causing variants reported in $\mathrm{HGMD}{ }^{\circledR}$, in ClinVar, or CentoMD® are evaluated. The investigation for relevant variants is focused on coding exons and flanking $+/-10$ intronic nucleotides of genes with clear gene-phenotype evidence (based on OMIM® information).

- It revealed the presence of a homozygous Frameshift mutation (NM_152281.2:c.306dup) The GORAB variant c.306dup p. (Pro103Thrfs*20) introduces a premature stop codon, that leads to the creation of a truncated protein. According to HGMD Professional 2020.3, this variant has previously been described in several patients/families with gerodermia osteodysplasticum
(PMID: 19681135, 27023906, 29620724) [13]. It is classified as likely pathogenic (class 2 ) according to the recommendations of CENTOGENE and ACMG

- To date, 19 different GORAB mutations associated with OG syndrome have now been documented including seven missense/ nonsense, one splicing, two small deletions, one small insertion, one small indel, and one gross deletion (Table 1). These mutations had been reported from $\mathrm{OG}$ families from Saudi, Germany, Libya, Canada, Pakistan, Mexico, Italy, and United States. Azerbaijani $[9,11,12]$. In the reported OG gene mutations, more than one family from a common geographical area has been identified. These observations highlight that those mutations are ancestral and point to a distinct founder effect

- A differential diagnosis of GO with clinical phenotype overlap with other congenital disorder like cutis laxa, Ehlers-Danlos syndrome, Costello syndrome, and the progeroid syndromes [14].

\section{Conclusion}

We report a GO patient with homozygous GORAB mutations with different clinical features that have not been reported before as tall stature and arachnodactyly and crowded teeth the unusual finding and distinctive clinical phenotype of GO emphasizes the usefulness of advance molecular genetic test for diagnosis.

\section{Conflict of interest}

The authors have no conflicts of interest

\section{Acknowledgments}

We highly appreciate the patient for consenting and participating in this study. The work is supported by the Department of Genetics, Children's Hospital, King Saud Medical City, Riyadh, Saudi Arabia.

\section{Reference}

1. Al-Dosari, M., Alkuraya, F. S. (2009). A novel missense mutation in SCYL1BP1 produces geroderma osteodysplastica phenotype indistinguishable from that caused by nullimorphic mutations. Am. J. Med. Genet. 149A: 2093-2098, 2009.

2. Bamatter F. (1950). (Title not available). Med Hyg (Geneve). 1950;8(175 bis):287

3. Gazit E, Goodman RM, Katznelson BM and Rotem Y (1973). The wrinkly skin syndrome: A new heritable disorder of connective tissue. Clin Genet 4:186-192.

4. Goodman RM, Duksin D and Legum C (1982). The wrinkly skin syndrome and cartilage-hair hypoplasia (a new variant?) in 
sibs of the same family. In: Papdatos CJ and Bartsocas CS (eds) Progress in Clinical and Biological Research, 104: Skeletal Dysplasias. Alan R Liss, New York, pp 205-214.

5. Zlotogora J (1999). Wrinkly skin syndrome and the syndrome of cutis laxa with growth and development delay represent the same disorder. Am J Med Genet 85: 194.

6. Goyal et al., Ankur Singh, Kapoor, S. (2015) .The diagnostic dilemma of cutis laxa. Indian J. Dermatol.60, 521.

7. Egerer, Denise Emmerich, jörnFischer-Zirnsak, (2015). GORAB Missense Mutations Disrupt RAB6 and ARF5 Binding and Golgi Targeting. Journal of Investigative Dermatology, 2015; 135:2368-2376.

8. Ryojun Takeda, Masaki Takagi, Hiroyuki Shinohar. (2017). Novel compound heterozygous mutations identified by whole exome sequencing in a Japanese patient with geroderma osteodysplastica. European Journal of Medical Genetics (2017).

9. Rajab, A., Kornak, U., Budde, B. S., Hoffmann, K., Jaeken, J., Nurnberg, P., Mundlos, S. (2008). Geroderma osteodysplastica hereditaria and wrinkly skin syndrome in 22 patients from Oman. Am. J. Med. Genet. 146A: 965-976, 2008.
10. Eich, G. F., Steinmann, B., Hodler, J., Exner, G. U., Giedion, A. (1996). Metaphyseal peg in geroderma osteodysplastica: a new genetic bone marker and a specific finding? Am. J. Med. Genet. 63: 62-67, 1996

11. Hennies HC, Kornak U, Zhang H, Egerer J, Zhang X. et all (2008). Gerodermia osteodysplastica is caused by mutations in SCYL1BP1, a Rab-6 interacting golgin. Nat Genet 40: 1410 1412

12. Mohammed Al-Bughaili, Teresa M Neuhann, Ricarda Flöttmann. (2017). A de novo 1q23.3-q24.2 deletion combined with a GORAB missense mutation causes a distinctive phenotype with cutis laxa. journal of Human Genetics advance online publication, 8 September 2017

13. HGMD® gene result (cf.ac.uk)

14. Carlos Eduardo Steiner, Maria Letícia Cintra, and Antonia Paula Marques-de-Faria. (2005). Cutis laxa with growth and developmental delay, wrinkly skin syndrome and gerodermia osteodysplastica: A report of two unrelated patients and a literature review. Genetics and Molecular Biology, 28, 2, 181$190(2005)$
This work is licensed under Creative Commons Attribution 4.0 License

\section{To Submit Your Article Click Here: Submit Manuscript}

DOI: $10.31579 / 2690-1919 / 207$

\author{
Ready to submit your research? Choose Auctores and benefit from: \\ $>$ fast, convenient online submission \\ $>$ rigorous peer review by experienced research in your field \\ $>$ rapid publication on acceptance \\ $>$ authors retain copyrights \\ $>$ unique DOI for all articles \\ $>$ immediate, unrestricted online access
}

At Auctores, research is always in progress.

Learn more auctoresonline.org/journals/journal-of-clinical-research-andreports 